\section{Pengaruh Kualitas Pelayanan Terhadap Kepuasan Pasien Pada Rumah Sakit Umum Daerah Kota Cilegon}

\author{
Mahfudhoh $^{1}$ dan Ikhwanul Muslimin ${ }^{2}$ \\ ${ }^{1}$ Dosen Tetap STIE Al Khairiyah, ${ }^{2}$ Mahasiswa STIE Al Khairiyah \\ E-Mail: ${ }^{1}$ mahfudhoh774@gmail.com
}

Customer

Satisfaction and Service Quality

\title{
ABSTRACT
}

The hospital is a public facility owned by the government and the private sector which has a very strategic role in efforts to improve public health services. The new health care paradigm requires hospitals to provide quality services according to the needs and desires of patients while still referring to the professional and medical code of ethics. In the rapid development of technology and increasingly fierce competition, the hospital is required to improve the quality of its services. Quality is the core survival of an institution. Therefore, hospitals are required to always maintain consumer confidence by increasing the quality of service so that customer satisfaction increases. This study aims to analyze the influence of service quality on patients satisfaction. The research method used in this study is a survey method with correlation techniques. Data collection techniques using observation, interviews, and questionnaires (questionnaire). The results showed that the analysis of variable $X$ obtained an average of 3.55 , meaning that the quality of service at the Regional General Hospital (RSUD) of Cilegon City was in the Good category of 72.67\%. Analysis of variable $Y$ obtained an average of 3.50 , which means that patient satisfaction at the Regional General Hospital (RSUD) of Cilegon City is in the good category of 70.1\%. Analysis of product moment coefficient obtained $r=0.511$ means that it has a moderate correlation between variable $X$ and variable $Y$. The relationship pattern of variables is shown by a simple linear regression equation that is $Y=14.614+0.563 X$. It shows that the variance that occurs in the variable quality of service can affect performance by $26 \%$, while the remaining $74 \%$ is influenced by other factors not examined.

Keywords : service quality, patient satisfaction, hospital

\begin{abstract}
ABSTRAK
Rumah sakit merupakan sebuah fasilitas umum yang dimiliki oleh pemerintah maupun swasta yang memiliki peran yang sangat strategis dalam upaya meningkatkan pelayanan kesehatan masyarakat. Paradigma baru pelayanan kesehatan mensyaratkan rumah sakit memberikan pelayanan berkualitas sesuai kebutuhan dan keinginan pasien dengan tetap mengacu pada kode etik profesi dan medis. Dalam perkembangan teknologi yang pesat dan persaingan yang semakin ketat, maka rumah sakit dituntut untuk melakukan peningkatan kualitas pelayanannya. Kualitas merupakan inti kelangsungan hidup sebuah lembaga. Oleh karena itu, rumah sakit dituntut untuk selalu menjaga kepercayaan konsumen dengan meningkatkan kualitas pelayanan agar kepuasan konsumennya meningkat. Penelitian ini bertujuan untuk menganalisis pengaruh kualitas pelayanan terhadap kepuasan pasien Rumah Sakit Umum Daerah (RSUD) Kota Cilegon. Metode penelitian yang digunakan dalam penelitian ini adalah metode survei dengan teknik korelasi. Teknik pengumpulan data menggunakan observasi, wawancara, dan angket (quisioner). Hasil penelitian menunjukkan bahwa analisis variabel $\mathrm{X}$ diperoleh rata-rata 3,55 artinya kualitas pelayanan pada Rumah Sakit Umum Daerah (RSUD) Kota Cilegon ada dalam kategori Baik sebesar 72,67\%. Analisis
\end{abstract}

Submitted: APRIL 2020

Accepted: APRIL 2020

\section{JIMKES}

Jurnal Ilmiah Manajemen Kesatuan Vol. 8 No. 1,2020
pp. $39-46$ pp. 39-46
IBI Kesatuan ISSN $2337-7860$ E-ISSN 2721 - 169X 
Customer

Satisfaction and

Service Quality variabel Y diperoleh rata-rata 3,50 artinya kepuasan pasien pada Rumah Sakit Umum Daerah (RSUD) Kota Cilegon ada dalam kategori baik sebesar 70,1\%. Analisis koefisien produk moment diperoleh $\mathrm{r}=0,511$ artinya memiliki korelasi sedang antara variabel $\mathrm{X}$ terhadap variabel $\mathrm{Y}$. Pola hubungan variabel ditunjukkan dengan persamaan regresi linear sederhana yaitu $\mathrm{Y}=14,614+0,563 \mathrm{X}$. hal tersebut menunjukkan bahwa varian yang terjadi pada variabel kualitas pelayanan dapat mempengaruhi kinerja sebesar $26 \%$, sedangkan sisanya sebesar $74 \%$ dipengaruhi oleh faktor-faktor lain yang tidak diteliti.

Kata kunci : kualitas produksi, harga, promosi, pelayanan, kepuasan, keputusan pembelian

\section{PENDAHULUAN}

Kepuasan konsumen merupakan perbandingan dan keyakinan konsumen terhadap pelayanan yang diberikan oleh rumah sakit dalam bentuk kinerja. Tingkat kualitas pelayanan di anggap memuaskan jika kualitas yang diberikan melebihi harapan maka dapat dipersepsikan ideal. Pegawai suatu instansi pada dasarnya merupakan suatu sumber utama organisasi yang tidak dapat digantikan oleh sumber daya lainnya karena baik buruknya suatu instansi dilihat dari pelayanan dan fasilitasnya serta sarana tidak akan bermanfaat tanpa adanya pegawai yang mengatur. Menurut keputusan menteri pendayagunaan aparatur negara (Kepmen PAN) Nomor 58 Tahun 2002 yang menyatakan ada tiga jenis pelayanan yaitu pelayanan administratif, pelayanan barang, pelayanan jasa yang diberikan oleh penyedia layanan dalam instansi BUMN atau BUMD. Pada penelitia ini akan membahas dari jenis dari pelayanan jasa yang didalamnyatermasuk pelayanan jasa kesehtan. Pelayanan kesehatan yang bersentuhan langsung dengan masyarakat tentunya termasuk dalam ruang lingkup pelayanan publik, pada penelitian ini akan $b$ erfokus pada pelayanan publik dibidang jasa kesehtan di Rumah Sakit Umum Daerah milik Pemerintah Kota Cilegon. Rumah Sakit sebagai penyedia layanan jasa kesehatan harusnya memperhatikan kebutuhan dan kepuasan pasien pengguna layanan kesehatan.

Rumah sakit memiliki peran yang sangat strategis dalam upaya mempercepat peningkatan derajat kesehatan masyarakat. Paradigma baru pelayanan kesehatan mensyaratkan rumah sakit memberikan pelayanan berkualitas sesuai kebutuhan dan keinginan pasien dengan tetap mengacu pada kode etik profesi dan medis. Dalam perkembangan teknologi yang pesat dan persaingan yang semakin ketat, maka rumah sakit dituntut untuk melakukan peningkatan kualitas pelayanannya. Kualitas merupakan inti kelangsungan hidup sebuah lembaga. Gerakan revolusi mutu melalui pendekatan manajemen mutu terpadu menjadi tuntutan yang tidak boleh diabaikan jika suatu lembaga ingin hidup dan berkembang. Persaingan yang semakin ketat akhir-akhir ini menuntut sebuah lembaga penyedia jasa/layanan untuk selalu memanjakan pelanggan/konsumen dengan memberikan pelayanan terbaik. Para konsumen akan mencari produk berupa barang atau jasa dari perusahaan yang dapat memberikan pelayanan yang terbaik kepadanya. Masalah utama sebagai sebuah lembaga jasa pelayanan kesehatan adalah semakin banyaknya pesaing. Oleh karena itu, rumah sakit dituntut untuk selalu menjaga kepercayaan konsumen dengan meningkatkan kualitas pelayanan agar kepuasan konsumennya meningkat.

Pelayanan kesehatan di Rumah Sakit Umum Daerah (RSUD) kota Cilegon selalu mendapatkan sorotan dari masyarakat. Pelayanan yang kurang memuaskan, ketidakramahan petugas medis maupun nonmedis, kurang cekatan, dan peralatan atau perlengkapan yang kurang layak pakai. Selain permasalahan tentang keramahan, pasien lainnya mengeluh tentang keterlambatan perawat dalam menangani pasien. Kualitas pelayanan sangat penting dilakukan di RSUD Cilegon, mengingat RSUD adalah sarana umum yang di bangun oleh pemerintah untuk peningkatan kesehatan masyarakat, maka sangat tidak pantas bila sarana publik pelayanannya kurang baik RSUD seperti antrian yang cukup lama, kurangnya fasilitas peralatan rumah sakit, kurang cekatannya para 
pekerja yang ada di RSUD. Seperti permasalahan yang terjadi di RSUD, karena pelayanannya yang kurang baik, sehingga banyaknya keluhan masyarakat atas pelayanan yang kurang baik di dalam RSUD, mengingat RSUD adalah pelayanan publik yang seharusnya kualitas dan prasarananya harus ditingkatkan agar terciptanya kenyamanan untuk masyrakat. Berdasarkan penjelasan sebelumnya sebuah perusahaaan jasa seperti rumah sakit harus menjaga kualitas jasa yang ditawarkan karena bila kualitas jasa yang didapatkan oleh pasien melebihi harapannya maka akan terbentuk suatu loyalitas pasien terhadap rumah sakit tersebut begitupun sebaliknya.

Menurut Triguno, kualitas sebagai standar yang harus dicapai oleh seseorang/ kelompok/lembaga/organisasi mengenai kualitas sumber daya manusia, kualitas cara kerja, proses, dan hasil kerja atau produk yang berupa barang dan jasa, eksternal, dalam arti optimal pemenuhan atas tuntutan/persyaratan pelanggan/ masyarakat. Menurut Ratminto \& Atik Septi Winarsih, dan ini juga bisa dijadikan sebagai indikator untuk kepuasaan pelayanan : (1) Tangibles atau ketampakan fisik artinya ketampakan fisik dari gedung, peralatan, pegawai, dan fasilitas-fasilitas lain yang dimiliki oleh providers. (2) Reliability atau reabilitas adalah kemampuan untuk menyelenggarakan pelayanan yang dijanjikan secara akurat. (3) Responsiveness atau responsivitas adalah kerelaan untuk menolong customer dan menyelenggarakan pelayanan secara ikhlas. (4) Assurance atau kepastian adalah pengetahuan dan kesopanan para pekerja dan kemampuan mereka dalam memberikan kepercayaan kepada customers. (5) Empathy adalah perlakuan atau perhatian pribadi yang diberikan oleh provider kepada customers.

Menurut Nina Rahmayanty, Variabel terikat yaitu kepuasan konsumen, yang penulis simbolkan dengan huruf Y, memiliki indikator sebagai berikut: (1) Keamanan : Proses dan produk pelayanan memberikan rasa aman dan kepastian hukum. (2) Kejelasan : Kejelasan disini mulai dari persyaratan administratif sampai dengan biaya pelayanan serta tata cara pembayaran yang benar. (3) Kelengkapan Sarana dan Prasarana : Tersedianya sarana dan prasarana kerja, peralatan keja dan pendukung lainya yang memadai termasuk penyediaan teknologi komunikasi dan informatika. (4) Kepastian waktu : Pelaksanaan pelayanan dapat diselesaikan dalam kurun waktu yang telah ditentukan. (5) Kedisiplinan, Kesopanan, dan Keramahan : Pemberi pelayanan harus bersikap disiplin,sopan dan santun,ramah,serta memberikan pelayanan dengan ikhlas.

\section{METODE PENELITIAN}

Metode penelitian yang digunakan adalah metode survei dan penelitian ini bersifat asosiatif kausal yang membahas dua variabel yaitu variabel independen (variabel yang mempengaruhi) dan variabel dependen (variabel yang dipengaruhi) Penelitian ini dilakukan untuk mencapai hubungan atau pengaruh satu variabel dengan variabel yang lain. Populasi penelitian ini adalah 912 pasien/masyarakat yang datang ke RSUD Kota Cilegon selama tiga bulan terakhir yaitu pada bulan Mei, Juni, dan Juli tahun 2018. Jumlah sampel yang diambil pada penelitian ini digunakan rumus Slovin dengan presentase kelonggaran kesalahan dalam pengambilan sampel yang masih di tolerir atau diinginkan yaitu $10 \%$. Sehingga sampel penelitian ini adalah 90 orang. Adapun teknik pengambilan sampel untuk penelitian ini penulis menggunakan teknik random sampling (sampel acak) yaitu teknik pengambilan sampel dari semua konsumen secara acak tanpa memperhatikan strata yang ada dalam populasi. Jenis data yang digunakan dalam penelitian ini adalah data primer dan sekunder. Adapun metode yang digunakan dalam penelitian ini adalah observasi, wawancara, kepustakaan dan menyebar kuesioner kepada para pasien. Teknik analisa yang di lakukan meliputi; deskripsi data, uji persyaratan analisis, uji instrument, dan uji hipotesis (uji korelasi produk momen, uji koefisien determinasi, uji signifikasi dan regresi linier).
Customer
Satisfaction and
Service Quality

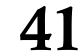


Customer

Satisfaction and

Service Quality
HASIL DAN PEMBAHASAN

Deskripsi Data

RSUD Kota Cilegon memiliki jumlah SDM sebanyak 660 orang, dengan rincian tenaga medis sebanyak 77 Orang, ahli gizi sebanyak 11 Orang, tenaga keperawatan sebanyak 257 Orang, tenaga kefarmasian sebanyak 9 Orang, Keteknisian Medis sebanyak 9 Orang, Keterapian Fisik sebanyak 6 Orang, Kesehatan Masyarakat sebanyak 8 Orang, Non Kesehatan sebanyak 244 Orang, dan Bidan sebanyak 39 Orang (sumber : Profil RSUD Kota Cilegon 2015). Data yang penulis peroleh dalam penelitian ini berbentuk kuantitatif yang berasal dari responden yaitu pasien pada RSUD Cilegon sebanyak 90 orang (sampel) dengan 20 pertanyaan yang terbagi dalam 10 pertanyaan untuk variabel X (kualitas pelayanan) dan 10 pertanyaan untuk variabel Y (kepuasan pasien)

\section{Analisis Data Variabel Kualitas Pelayanan}

Setelah dilakukan analisis dari 90 hasil jawaban kuesioner yang diajukan kepada pasien dari RSUD Kota Cilegon, maka didapatkan jumlah skor kriterium (bila setiap butir mendapat skor tertinggi) $=5 \times 10 \times 90=4500$ dan (bila setiap butir mendapat skor terendah) $=1 \times 10 \times 90=$ Untuk ini skor tertinggi 5 dan terendah 1 , jumlah butir 10 dan jumlah responden 90. Jumlah skor pengumpulan data untuk kualitas pelayanan yaitu $=$ 3270. Dengan demikian kualitas pelayanan diperlukan menurut persepsi 90 responden yaitu $3270: 4500=0,7267$ atau $72,67 \%$ dari kriteria yang ditetapkan, hal ini secara kontinum dapat dibuat kategori sebagai berikut :

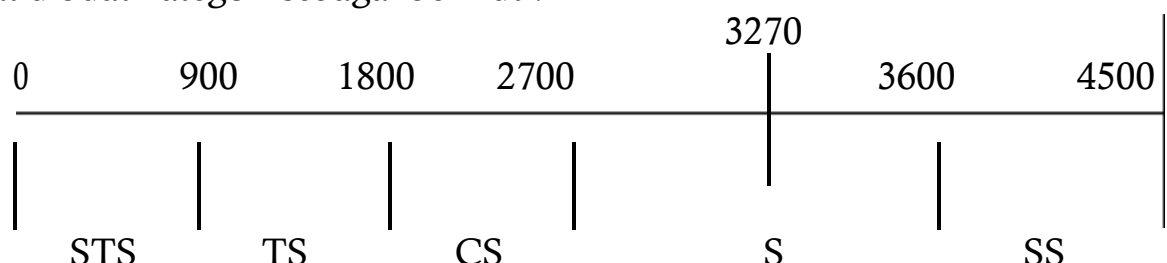

\section{Analisis Data Variabel Y (Kepuasan Konsumen)}

Gambar 1 Analisis Kualitas Pelayanan

Setelah dilakukan analisis dari 90 hasil jawaban kuesioner yang diajukan kepada pasien di RSUD Cilegon, maka hasil didapatkan jumlah skor kriterium (bila setiap butir mendapat skor tertinggi) $=5 \times 10 \times 90=4500$ dan (bila setiap butir mendapat skor terendah) $=1 \times 10 \times 90=$ Untuk ini skor tertinggi 5 dan terendah 1 , jumlah butir 10 dan jumlah responden 90. Jumlah skor pengumpulan data untuk Kepuasan Pasien yaitu $=$ 3156 (lihat lampiran 2). Dengan demikian Kepuasan Pasien di perlukan menurut persepsi 90 responden yaitu $3156: 4500=0,701$ atau $70,1 \%$ dari kriteria yang ditetapkan, hal ini secara kontinum dapat dibuat kategori sebagai berikut :

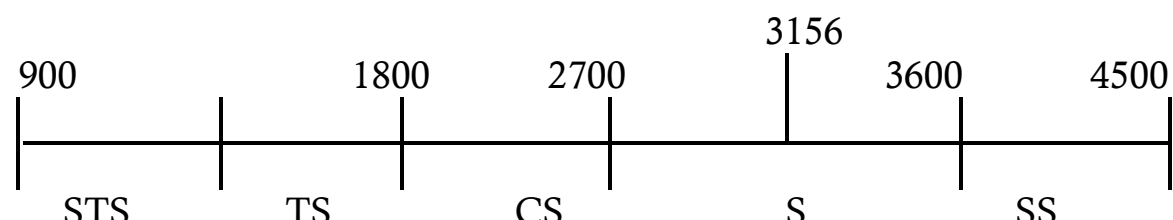

Gambar 2 Analisis Kepuasan Pasien

\section{Uji Instrumen}

\section{Uji Validitas}

Uji validitas bertujuan untuk mengetahui tingkat akurasi yang dicapai oleh sebuah indikator dalam menilai sesuatu atau keakuratan pengukuran atas apa yang seharusnya diukur.

Berdasarkan tabel 1, semua instrument Variabel Kualitas Pelayanan adalah valid, untuk instrument tersebut dapat dipergunakan untuk penelitian selanjutnya

Berdasarkan tabel 1, semua instrument Variabel Kepuasan Pasien adalah valid, untuk instrument tersebut dapat dipergunakan untuk penelitian selanjutnya. 


\begin{tabular}{cccccccc}
\hline \multicolumn{3}{c}{ KUALITAS PELAYANAN } & \multicolumn{5}{c}{ KEPUASAN PASIEN } \\
No Instrumen & Rhitung & rtabel & Keputusan & No Instrumen & Rhitung & rtabel & Keputusan \\
\hline 1 & 0,426 & 0,207 & Valid & 1 & 0,579 & 0,207 & Valid \\
2 & 0,566 & 0,207 & Valid & 2 & 0,292 & 0,207 & Valid \\
3 & 0,515 & 0,207 & Valid & 3 & 0,667 & 0,207 & Valid \\
4 & 0,421 & 0,207 & Valid & 4 & 0,505 & 0,207 & Valid \\
5 & 0,352 & 0,207 & Valid & 5 & 0,576 & 0,207 & Valid \\
6 & 0,503 & 0,207 & Valid & 6 & 0,515 & 0,207 & Valid \\
7 & 0,501 & 0,207 & Valid & 7 & 0,594 & 0,207 & Valid \\
8 & 0,491 & 0,207 & Valid & 8 & 0,652 & 0,207 & Valid \\
9 & 0,527 & 0,207 & Valid & 9 & 0,403 & 0,207 & Valid \\
10 & 0,489 & 0,207 & Valid & 10 & 0,557 & 0,207 & Valid \\
\hline
\end{tabular}

\section{Uji Reliabilitas}

Berdasarkan hasil dari perhitungan reliabilitas menggunakan SPSS versi 19.0 maka diperoleh $r_{\text {hitung }}(0,681)>r_{\text {tabel }}(0,207)$, dari perbandingan tersebut dapat disimpulkan bahwa valid dan reliabel.

Berdasarkan hasil uji reliabilitas indikator Kepuasan Pasien, bahwa nilai koefisien korelasi lebih besar dari nilai $r_{\text {tabel }}$ yaitu 0,207 maka dinyatakan reliabel, sehingga seluruh instrument dari kedua variabel dapat dinyatakan valid dan reliabel. Dengan demikian kedua variabel terebut dapat digunakan untuk pengujian selanjutnya.

Tabel 3 Reliabilitas Kualitas Pelayanan

\begin{tabular}{|ll|r|}
\hline Cronbach's Alpha & Part 1 Value & 1,000 \\
& Nof Items & $1^{\mathrm{a}}$ \\
& Part 2 Value & 1,000 \\
& N of Items & $1^{\mathrm{b}}$ \\
& Total N of Items & 2 \\
Correlation Between Forms & &, 582 \\
Spearman-Brown Coefficient & Equal Length &, 736 \\
& Unequal Length &, 736 \\
Guttman Split-Half Coefficient & &, 735 \\
\hline
\end{tabular}

a. The items are : Ganjil X

b. The items are: Genap Y

Tabel 4 Reliabilitas Kepuasan Pasien

\begin{tabular}{|ll|r|}
\hline Cronbach's Alpha & Part 1 Value & 1,000 \\
& N of Items & $1 \mathrm{a}$ \\
& Part 2 Value & 1,000 \\
& N of Items & $1^{\mathrm{b}}$ \\
& Total N of Items &, 516 \\
Correlation Between Forms & &, 681 \\
Spearman-Brown Coefficient & Equal Length &, 681 \\
& Unequal Length &, 677 \\
\hline
\end{tabular}

a. The items are : Ganjil X

b. The items are : Genap Y

\section{Uji Korelasi Produk Moment Dan Koefisien Determinasi}

Uji korelasi product moment dan koefisien Determinasi dengan menggunakan perhitungan SPSS versi 19.0 diperoleh hasil $r_{\text {hitung }}$ sebesar 0,511 (lihat lampiran) maka termasuk ke dalam kategori sedang 
Customer

Satisfaction and

Service Quality
Tabel 5 Uji Korelasi Product Moment

\begin{tabular}{cc|l|c|c|c|}
\hline Model & $\mathrm{R}$ & $\mathrm{R}$ Square & $\begin{array}{c}\text { Adjusted R } \\
\text { Square }\end{array}$ & $\begin{array}{c}\text { Std. Error of the } \\
\text { Estimate }\end{array}$ & Durbin-Watson \\
\hline \multicolumn{1}{c|}{, $511^{\mathrm{a}}$} &, 261 &, 253 & 3,53193 & 2,010 \\
\hline
\end{tabular}

a. Predictors: (Constant), Kualitas Pelayanan

b. Dependent Variable: Kepuasan Pasien

Tabel 6 Interpretasi Koefisien Korelasi

\begin{tabular}{cc}
\hline Interval Koefisien & Tingkat Hubungan \\
\hline $0,00-0,199$ & Sangat Rendah \\
$0,20-0,399$ & Rendah \\
$0,40-0,599$ & Sedang \\
$0,60-0,799$ & Kuat \\
$0,80-1,000$ & Sangat Kuat
\end{tabular}

Dari hasil perhitungan koefisien korelasi diatas, maka untuk menentukan besar kecilnya hubungan variabel $\mathrm{X}$ dengan variabel $\mathrm{Y}$ dapat dicari dengan menggunakan rumus koefisien determinasi (cd), dengan menggunakan rumus matematika yaitu $\mathrm{cd}=\mathrm{r}^{2}$ x $100 \%$ maka diperoleh angka sebesar : $\mathrm{Cd}=0,511^{2} \times 100 \%=0,261121 \times 100 \%=$ 26,1121 atau dibulatkan menjadi $26 \%$. Hal tersebut menunjukkan bahwa varian yang terjadi pada variabel kualitas pelayanan dapat mempengaruhi variabel kepuasan pasien sebesar $26 \%$ sedangkan sisanya $74 \%$ dipengaruhi oleh variabel-variabel faktor-faktor yang tidak diteliti.

\section{Uji Signifikansi}

Tujuan untuk mengetahui tingkat signifikansi hubungan dari kedua variabel yaitu antara kualitas pelayanan terhadap kepuasan pasien atau untuk mengetahui koefisien korelasi, signifikansi atau tidaknya. Berdasarkan hasil perhitungan SPSS versi 19.0 diperoleh $t_{\text {hitung }}$ sebesar 5,576.

Tabel 7 Hasil Uji Regresi Linier Sederhana

\begin{tabular}{|c|c|c|c|c|c|c|}
\hline \multirow[t]{2}{*}{ Model } & \multirow[t]{2}{*}{ Items } & \multicolumn{2}{|c|}{$\begin{array}{l}\text { Unstandardized } \\
\text { Coefficients }\end{array}$} & $\begin{array}{l}\text { Standardized } \\
\text { Coefficients }\end{array}$ & \multirow[b]{2}{*}{$\mathrm{t}$} & \multirow[b]{2}{*}{ Sig. } \\
\hline & & B & Std. Error & Beta & & \\
\hline 1 & (Constant) & 14,614 & 3,687 & & 3,964 & ,000 \\
\hline & KualitasPelayanan & ,563 & 101 & 511 & 5,576 & ,000 \\
\hline
\end{tabular}

a. Dependent Variable: kepuasan pasien

Kemudian $t_{\text {hitung }}$ tersebut dibandingkan dengan $t_{\text {tabel }}$ dalam hal ini tingkat kesalahan untuk uji dua pihak adalah dengan menggunakan alpha $5 \%(0,05)$ dengan derajat kebebasan $\mathrm{dk}=\mathrm{n}-2=88$ ( $\mathrm{n}$ adalah jumlah sampel 90 orang), maka berdasarkan nilainilai dalam distribusi untuk $t_{\text {tabel }}$ dengan jumlah sampel 88 responden yaitu 1,66235. Nilai $t_{\text {hitung }}$ tersebut selanjutnya dibandingkan dengan nilai $t_{\text {tabel }}$. Dalam penelitian ini untuk tingkat kesalahan diambil 5\% uji dua pihak dan dk (derajat kebebasan) $=\mathrm{n}-2$. Dengan demikian diperoleh $t_{\text {tabel }}$ sebesar 1,66235. Berdasarkan kriteria pengujian hipotesis terhadap nol $\left(\mathrm{H}_{0}\right)$, yaitu $\mathrm{H}_{0}$ ditolak jika $\mathrm{t}_{\text {hitung }}>\mathrm{t}_{\text {tabel }}$. Diperoleh $\mathrm{t}_{\text {hitung }} 5,576>\mathrm{t}_{\text {tabel }}$ 1,66235 maka hipotesis nol $\left(\mathrm{H}_{0}\right)$ ditolak, dan menerima hipotesis alternative $\left(\mathrm{H}_{\mathrm{a}}\right)$ dengan pernyataan yaitu : "Terdapat Pengaruh Kualitas Pelayanan terhadap Kepuasan Pasien pada Rumah Sakit Umum Daerah (RSUD) Kota Cilegon"

\section{Uji Regresi Linier Sederhana}

Berdasarkan hubungan variabel dalam penelitian ini bersifat kausal atau sebab akibat, maka dapat dibuat persamaan regresi linear sederhana yaitu $Y=a+b X$. Sedangkan untuk nilai a dan $b$ diperoleh dengan menggunakan perhitungan SPSS versi 19.0, yaitu $\mathrm{a}=14,614$ sedangkan nilai $\mathrm{b}$ adalah $\mathrm{b}=0,563$. Maka dapat dipperoleh persamaan regresi linear sederhananya yaitu $\mathrm{Y}=14,614+0,563 \mathrm{X}$. 


\section{PENUTUP}

Kesimpulan Berdasarkan hasil penelitian yang penulis teliti, diketahui indikator tertinggi pada variabel X (Kualitas Pelayanan) yaitu pada indikator Ketampakan Fisik, dengan nilai $22 \%$. Sedangkan untuk indikator terendah pada indikator Responsivitas, dengan nilai 17,23\%. Berdasarkan hasil penelitian yang penulis teliti, diketahui indikator tertinggi pada variabel Y (Kepuasan Pasien) yaitu pada indikator Keamanan, dengan nilai 21,84\% menjawab setuju. untuk indikator terendah Kelengkapan, dengan nilai $18,67 \%$. Saran Dari kesimpulan di atas dapat di simpulkan bahwa indikator terendah kualitas pelayanan adalah Responsivitas sebesar 17,23\%. Penilaian responden terhadap kualitas pelayanan yang diberikan oleh Rumah Sakit Umum Daerah (RSUD) Kota Cilegon. Instansi diharapkan dapat bersedia membantu keperluan pasien dan respon yang dilakukan dengan baik apabila ada komplain, Sedangkan untuk indikator terendah kepuasan pasien adalah Kelengkapan sebesar 18,67\%. Instansi diharapkan dapat menyediakan obat-obatan atau alat-alat medis yang lengkap dan peralata atau perlengkapan masih layak pakai untuk pasien.

\section{DAFTAR PUSTAKA}

[1] Arikunto, Suharsimi. 2010. Prosedur Penelitian, Cetakan Empat Belas. PT Rineka Cipta. Jakarta.

[2] Bahudin, Zaenal. 2010. Pengaruh Kualitas Pelayanan Terhadap Kepuasan Masyarakat Pada Kecamatan Cibeber. Skripsi. Cilegon. STIE Al-Khairiyah.

[3] Dewi, Meutia. 2016. Pengaruh Kualitas Pelayanan terhadap Kepuasan Pasien Pengguna BPJS pada Rumah Sakit Rehabilitasi Medik Kabupaten Aceh Timur. Jurnal Manajemen Dan Keuangan, Vol.5, No.2, November 2016.

[4] Dorothea. 2012. Manajemen Kualitas, Cetakan Ke Tiga. Ghalia Indonesia. Bogor.

[5] Gasperz, Vincent. 2017. Manajemen Kualitas Dalam Industri Jasa. PT. Gramedia Pustaka Utama. Jakarta.

[6] Hanyani, T. and Fadillah, A., 2013. Pengaruh Kualitas dan Diferensiasi Produk Terhadap Loyalitas Pelanggan. Jurnal Ilmiah Manajemen Kesatuan, 1(3), pp.237-246.

[7] Hasibuan, Malayu S.P. 2017. Manajemen Sumber Daya Manusia, Cetakan Ke-21. PT Bumi Aksara. Jakarta.

[8] Irbantoro, Dolly., Aryo Dewanto dan Asih Tri Rachmi N. 2015. Pengaruh Kualitas Pelayanan Terhadap Kepuasan Pasien Rawat Inap di Rumah Sakit Kota Batu. Jurnal Aplikasi Manajemen Volume 13 Nomor 1 Maret 2015.

[9] Munawar, A. and Purba, J.H.V., 2006. Kajian Dampak Pelatihan terhadap Kinerja Karyawan. Jurnal Ilmiah Kesatuan Nomor, 8(7), p.2.

[10] Nasution, M. Nur. 2010. Manajemen Mutu Terpadu, Edisi Ketiga. Ghalia Indonesia. Jakarta.

[11] Nazir, Moh. 2017. Metode Penelitian, Cetakan 11. Ghalia Indonesia. Bogor.

[12] Rahmayanty, Nina. 2013. Manajemen Pelayanan Prima. Graha Ilmu. Yogyakarta.

[13] Ratminto., dan Atik Septi Winarsih. 2014. Manajemen Pelayanan, Cetakan Ke 12. Pustaka Pelajar. Yogyakarta.

[14] Ratnasari, Ririn Tri., dan Mastuti. 2011. Manajemen Pemasaran Jasa. Ghalia Indonesia. Surabaya.

[15] Sohari. 2014. Pengaruh Kualitas Pelayanan Terhadap Kepuasan Konsumen Pada PD. Jamjuri. Skripsi. Cilegon. STIE Al-Khairiyah.

[16] Sugiyono. 2012. Metode Penelitian Bisnis, Cetakan Ke-16. CV Alfabeta. Bandung.

[17] Sugiyono. 2015. Metode Penelitian Kuantitatif Kualitatif DAN R\&D, Cetakan Ke22. Alfabeta. Bandung.

[18] Sulistiono, S., Nurendah, Y. and Mulyana, M., 2019. Mengukur Minat Studi Siswa SMA dan SMK di Kota Bogor Pada Program Studi Kewirausahaan. JAS-PT (Jurnal Analisis Sistem Pendidikan Tinggi Indonesia), 3(1), pp.1-12.

[19] Tjiptono, Fandy. 2015. Manajemen Jasa. Andi. Yogyakarta.
Satisfaction and Service Quality 
Customer Satisfaction and Service Quality
[20] Yulianti, Nona., dan Putu Nina Madiawati. 2015. Pengaruh Kualitas Pelayanan Terhadap Kepuasan Pasien Pada Unit Rawat Inap Rumah Sakit Dr. Hasan Sadikin Bandung. e-Proceeding of Management : Vol.2, No.2 Agustus 2015 | Page 2056.

[21] Zuhdi, S., Daud, A., Hanif, R., Nguyen, P.T. and Shankar, K., 2019. Role of Social Media Marketing in the Successful Implementation of Business Management. International Journal of Recent Technology and Engineering, 8. 